\title{
CICLO HERMENÊUTICO E A CONTRUÇÃO DA COMPREENSÃO HUMANA
}

\author{
HERMENEUTIC CYCLE AND THE CONSTRUCTION OF HUMAN UNDERSTANDING
}

Heracilia Costa Alencar ${ }^{1}$

\section{RESUMO}

O presente artigo reflete a respeito do círculo hermenêutico proposto pelo filósofo alemão Gadamer, que descreve o processo de compreender um texto hermeneuticamente. Em Verdade e Método o filósofo Gadamer aborda o ciclo hermenêutico com a influência interpretativa do "préconceito" como condição da compreensão, a importância da tradição e o historicismo. O autor demonstra que a ciência apenas admite como satisfação de verdade aquilo que satisfaz o ideal de certeza, evidenciando a hermenêutica ontológica e filosófica. Hans-Georg, discorre sobre o preconceito através do iluminismo, e ressalta a visão de Heidegger. Gadamer não se preocupou em elaborar um método, uma vez que, não se destina a resolver problemas hermenêuticos práticos, mas sim, a construir uma teoria acerca de questões preliminares ligadas ao fenômeno da compreensão. Para ele, a compreensão é como o modo de existência do próprio indivíduo em suas mais variadas possibilidades, ou seja, caracteriza-se como uma ontologia fundamental. Para a produção do trabalho utilizou-se pesquisa bibliográfica. Ademais, ressalta que o círculo não tem caráter de método para resolução de problemas hermenêuticos práticos, mas sim como intrínseco à construção da compreensão humana.

Palavras-chave: Círculo-Hermenêutico. Gadamer. Hermenêutica. Verdade.

\section{SUMMARY}

This article reflects on the hermeneutic circle proposed by the German philosopher Gadamer, which describes the process of understanding a hermeneutic text. In Truth and Method the philosopher Gadamer approaches the hermeneutic cycle with the interpretative influence of "preconcept" as a condition of understanding, the importance of tradition and historicism. The author demonstrates that science only admits as truth satisfaction that which satisfies the ideal of certainty, evidencing ontological and philosophical hermeneutics. Hans-Georg discusses prejudice through the Enlightenment, and emphasizes Heidegger's view. Gadamer was not concerned with devising a method, since it is not intended to solve practical hermeneutic problems, but rather to construct a theory about preliminary questions connected with the phenomenon of understanding. For him, understanding is like the individual's own mode of existence in its most varied possibilities, that is, it is characterized as a fundamental ontology. For the production of the work we used bibliographic research. Moreover, he points out that the circle has no character as a method for solving practical hermeneutic problems, but as intrinsic to the construction of human understanding.

Keywords: Circle-Hermeneutic. Gadamer Hermeneutics. Truth.

${ }^{1}$ Graduanda em Filosofia - UFMA. 


\section{INTRODUÇÃO}

Em Verdade e Método o filósofo Gadamer aborda o ciclo hermenêutico com a influência interpretativa do "pré-conceito" como condição da compreensão, a importância da tradição e o historicismo. $\mathrm{O}$ autor demonstra que a ciência apenas admite como satisfação de verdade aquilo que satisfaz o ideal de certeza, evidenciando a hermenêutica ontológica e filosófica. Hans-Georg, discorre sobre o preconceito através do iluminismo, e ressalta a visão de Heidegger.

Gadamer não se preocupou em elaborar um método, uma vez que, não se destina a resolver problemas hermenêuticos práticos, mas sim, a construir uma teoria acerca de questões preliminares ligadas ao fenômeno da compreensão. Para ele, a compreensão é como o modo de existência do próprio indivíduo em suas mais variadas possibilidades, ou seja, caracteriza-se como uma ontologia fundamental.

\section{A HERMENÊUTICA POR GADAMER}

A hermenêutica gadameriana é marcada pela análise heideggeriana da estrutura de antecipação da compreensão, de acordo com a qual compreende-se o mundo e os outros à luz do nosso horizonte ou contexto histórico, social e cultural. Segundo Heidegger, não há interpretação sem pressupostos, porque toda a interpretação é determinada por um contexto prático, por uma certa grelha conceptual e ainda pelo acolhimento de uma determinada perspectiva dentro do nosso horizonte de inteligibilidade.

Essa interpretação, compreensão nunca pode ser dispensada ou abolida, mas apenas elaborada e desenvolvida. Deste modo, a noção tradicional de círculo hermenêutico, que remetia para a dependência mútua do sentido das partes e do sentido do todo ao nível da compreensão de um texto, é reinterpretada como o movimento circular entre a pré-compreensão de um intérprete e o interpretado.

Assim, Gadamer avançou seus escritos indo ao encalço de como a hermenêutica pode ser digna da historicidade para a compreensão. Ao falar em historicidade o autor alude sobre a construção do "pré-conceito", o qual contribui para a formação de opiniões prévias. O autor coloca o problema de como achar a saída do cabo de força ${ }^{2}$ das próprias opiniões prévias. 
Entretanto, Gadamer destaca que o intérprete não pode, pressupor que o que é dito em um texto se encaixe sem rupturas nas próprias opiniões e expectativa, mas o intérprete deve proteger-se dos preconceitos que determinam sua compreensão, pois a hermenêutica se converte por si mesma num questionamento pautado na coisa, e já se encontra sempre determinada por este, assim aquele que quer compreender não pode se entregar, já desde o início, à casualidade de suas próprias opiniões prévias .

Diante da condição humana, naturalmente, há preconceitos legítimos ou justificáveis, o que leva a um questionamento antes inexistente. O pertencimento do homem a uma realidade histórica faz com que sua visão de mundo e sua possibilidade de conhecimento partam dos preconceitos que o cercam. É preciso, pois, “ver com outros olhos”.

Gadamer demonstra que é somente no iluminismo que o conceito de preconceito recebeu o matiz negativo. O ideal iluminista procurou descartar tudo aquilo que o impedia de seguir adiante em seus anseios progressistas, e se valeu de uma interpretação unilateral para pôr de lado qualquer tipo de preconceito, por caracterizá-lo como pensamento infundado, irracional.

A noção de preconceito sofreu grande influência negativa por parte do iluminismo, que viu nele um empecilho para a razão, cuja função é a busca pela verdade, a libertação do homem. Naquele momento, o iluminismo se preocupava tão somente com o que o homem poderia produzir a partir se sua capacidade intelectiva. O progresso estava nas mãos do sujeito, e para que ele o alcançasse seria necessário romper com quaisquer tipos de ideias, dogmas, conhecimentos infundados, partir do "nada" seria o caminho. Destruir os preconceitos, essa era a ordem.

Para Gadamer a razão somente existe como real e histórica, isto significa: a razão não é dona de si mesma, pois está sempre referida ao dado no qual se exerce. O Escritor destaca que a compreensão hermenêutica é um puro desvelar do texto a partir da história de seus efeitos diante dos preconceitos de um determinado intérprete. Ela é mais que um método científico, pois designa sobretudo uma capacidade natural do ser humano. Assim, Hans-Georg enfatiza que há uma leitura errônea dos termos preconceito e tradição pelos iluministas com sua razão progressista que destrói o passado visando um futuro.

Para o filósofo a hermenêutica tem de partir do fato de que quem quer compreender está vinculado com a coisa em questão que se expressa na transmissão. Ao ser submetido à 
interpretação, o intérprete deve fazer jus das informações e condições do texto, formulando e reformulando sua leitura sobre o mesmo. Com isso, o interpretante põe seus preconceitos ante o crivo do texto, num ciclo infinito e intermitente de interpretações. Em suma, esse constante projetar de novo é o que perfaz o movimento semântico de compreender e de interpretar. Por outro lado, Gadamer ressalta que a hermenêutica não estar vinculada à coisa em questão, ao modo de não ser totalmente questionável.

Segundo o entendimento de Gadamer a hermenêutica não tem a tarefa de desenvolver um procedimento da compreensão, mas esclarecer as condições sob as quais surge a compreensão. Mas essas condições não têm todas o modo de ser de um procedimento ou de um método de tal modo que quem compreende poderia aplicá-las por si mesmo .Por isso, para Hans- Georg a compreensão não é um comportamento somente reprodutivo, mas é, por sua vez, sempre produtivo.

Compreender não é compreender melhor, nem de saber mais, no sentido objetivo, em virtude de conceitos mais claros, nem no da superioridade básica que o consciente possui com respeito ao inconsciente da produção. Compreender é interpretar, e todo interpretar se desenvolve no médium de uma linguagem que pretende deixar falar o objeto e é, ao mesmo tempo, a linguagem própria de seu intérprete.

Gadamer entende que o verdadeiro sentido de um texto, tal como este se apresenta ao seu intérprete, não depende do aspecto puramente ocasional que representam o autor e seu público originário. Ou pelo menos não se esgota nisso. Pois esse sentido está sempre determinado também pela situação histórica do intérprete, e, por consequência, por todo processo objetivo histórico, ou seja a fonte da pré-compreensão .

A importância do reconhecimento da pré-compreensão como condição da compreensão é justamente a de fazer ouvir a tradição, fazer valer a tradição legítima, aquela que corresponde fielmente às práticas reiteradas em coletividade e que por isso reclamam autoridade, não como mera coerção, mas como reconhecimento. Reconhecer a validade da tradição é simplesmente reconhecer que o processo de compreensão se dá dentro de um mundo concreto, preexistente, e que constitui o solo firme de qualquer intento interpretativo. 
Por seu turno, Gadamer aborda a hermenêutica por sua distância temporal, ou seja a interpretação mediante a distância da produção e o tempo em que este é interpretado.

$\mathrm{O}$ autor esclarece que o texto que se quer interpretar possui um horizonte, assim como o indivíduo que o interpreta. Esse horizonte de sentido se dá conjuntamente com o caso concreto e tudo isso está contido e ao mesmo tempo realiza a tradição, assim a elaboração da situação hermenêutica significa a obtenção do horizonte de questionamento correto para as questões que se colocam frente à tradição. Não se trata pois, de tentar retornar ao passado para enxergar com os olhos do passado, mas encontrar a presença do passado também no presente e vice-versa.

O conceito de horizonte, aludido pelo autor é o âmbito de visão que abarca e encerra tudo o que pode ser visto a partir de um determinado ponto. $\mathrm{O}$ termo horizonte indica, além da situação hermenêutica, o conjunto herdado de preconceitos. O conceito de horizonte também indica que o próprio horizonte do intérprete pode mudar através da adoção de outros preconceitos. A partir da situação, é visto o horizonte, um sujeito quando conversa com o outro, com o único propósito de conhecê-lo.

$\mathrm{Na}$ verdade trata-se de reconhecer a distância de tempo como uma possibilidade positiva e produtiva do compreender. Não é um abismo devorador, mas está preenchido pela continuidade da herança histórica e da tradição,.

O autor enfatiza que quando o intérprete procura entender um fenômeno histórico a partir da distância histórica que determinada situação hermenêutica, como um todo, encontra-se sempre sob os efeitos da história efeitual. Ela determina de antemão o que se mostra ao intérprete de modo questionável. A tarefa da compreensão histórica inclui a exigência de ganhar em cada caso o horizonte histórico, a fim de que se mostre, assim, o que se quer compreender em suas verdadeiras medidas.

Ressalta ,ainda , que quem se omite do deslocar-se ao horizonte histórico a partir do qual fala a tradição, estará sujeito a mal-entendidos com respeito ao significado dos conteúdos daquela. Nesse sentido, parece ser uma exigência hermenêutica justificada a importância do leitor ou ouvinte se colocar no lugar do outro para poder entendê-lo. A consciência histórica opera de um modo análogo, quando se desloca para a situação do passado e supõe ter assim seu verdadeiro horizonte histórico. E tal como no diálogo, o outro se torna compreensível em suas 
opiniões, a partir do momento em que se tornou reconhecida sua posição e horizonte, sem que, no entanto, isso implique no fato de que o crítico se entenda com o autor .

Hans-Georg esclarece que não é exigência que a história efeitual seja nova disciplina auxiliar das ciências do espírito, mas que se aprenda a conhecer-se melhor a si mesmo e se reconheça que os efeitos da história efeitual operam em toda compreensão, esteja ou não consciente disso. Para o autor quando há negação da história efeitual na ingenuidade da fé metodológica, a consequência pode ser até uma real deformação do conhecimento. Isso é conhecido através da história da ciência, como a execução de uma prova irrefutável de coisas evidentemente falsas, mas em seu conjunto, o poder da história efeitual não depende de seu reconhecimento. Isso, porém, não significa, de modo algum, que ela pudesse se realizar pura e simplesmente.

\section{CONSIDERAÇÕES FINAIS}

Assim, conclui-se que a hermenêutica gadameriana enfatiza a importância tradição no processo de interpretação como uma das muitas formas de realização das relações humanas de mundo. Assim, pautada historicidade a interpretação hermenêutica garante ao intérprete compreender e interpretar a comunidade da qual é parte, a partir de seu tempo e seu ser.

\section{REFERÊNCIAS}

ABBAGNANO, N. Dicionário de Filosofia. São Paulo: Martins Fontes, 2007.

ALMEIDA, Custódio. Hermenêutica e dialética: substituição ou complementação? São Leopoldo: Filosofia Unisinos, Volume 3, n²4, 2002.

BATISTA, Gustavo S. Hermenêutica e Práxis em Gadamer. Rio de Janeiro, 2007. 96p. Dissertação (Mestrado em Filosofia) - Departamento de Filosofia, Pontifícia Universidade Católica do Rio de Janeiro.

BLEICHER, Josef. Hermenêutica Contemporânea. Tradução de Maria Georgina Segurado. Lisboa: Edições 70, 1992.

DOSTAL Robert J. Gadamer's philosophical hermeneutics. In: The Cambridge Companion to Gadamer. Cambridge: Cambridge University Press, 2002. 
GADAMER, Hans-Georg. Verdade e Método vol.I: traços fundamentais de uma hermenêutica filosófica: volume 1: Verdade e Método I. 15 a ed. Petrópolis, RJ: Editora Vozes, 2015.

GADAMER, Hans - Georg. O problema da consciência histórica. Org. Pierre Fruchon. Trad. Paulo César Duque Estrada. Rio de Janeiro: Editora Fundação Getúlio Vargas, 1998.

GADAMER, Hans-Georg. Hermenêutica em Retrospectiva: A posição da filosofia na sociedade. Volume IV. Tradução de Marco Antônio Casanova. Petrópolis, RJ: Ed. Vozes, 2007.

GRONDIN, Jean. Gadamer's Basic Understanding of Understanding. In: The Cambridge Companion to Gadamer. Cambridge: Cambridge University Press, 2002.

GRONDIN, Jean. Gadamer on Humanism. The Philosophy of Hans-Georg Gadamer. The Library of living philosophers. Volume XXIV, 1997.

GRONDIN, Jean. Introducción a Gadamer. Tradução de C.R. Garrido. Barcelona: Herder, 2003.

HEIDEGGER, Martin. Ser e Tempo. Tradução revisada de Márcia Sá Cavalcante Schuback; Posfácio de Emmanuel Carneiro Leão. Petrópolis, Vozes; Bragança Paulista, SP: Editora Universitária São Francisco, 2006. 